\title{
Behavior Evolution of Multi-Group in the Process of Pedestrian Crossing Based on Evolutionary Game Theory
}

\author{
Ran Zhang ${ }^{1}$, Zhonghua Wei ${ }^{1}$, Heng Gu ${ }^{1}$ and Shi Qiu ${ }^{2, *}$ \\ 1 Faculty of Architecture, Civil and Transportation Engineering, Beijing University of Technology, \\ Beijing 100124, China; zhangran@emails.bjut.edu.cn (R.Z.); weizhonghua@bjut.edu.cn (Z.W.); \\ guheng@emails.bjut.edu.cn (H.G.) \\ 2 School of Civil Engineering, Central South University, Changsha 410083, China \\ * Correspondence: qshi7777@gmail.com
}

check for updates

Citation: Zhang, R.; Wei, Z.; Gu, H.; Qiu, S. Behavior Evolution of Multi-Group in the Process of Pedestrian Crossing Based on Evolutionary Game Theory. Sustainability 2021, 13, 2009. https:// doi.org/10.3390/su13042009

Academic Editor: Jacek Oskarbski

Received: 2 February 2021

Accepted: 9 February 2021

Published: 13 February 2021

Publisher's Note: MDPI stays neutral with regard to jurisdictional claims in published maps and institutional affiliations.

Copyright: (c) 2021 by the authors. Licensee MDPI, Basel, Switzerland. This article is an open access article distributed under the terms and conditions of the Creative Commons Attribution (CC BY) license (https:// creativecommons.org/licenses/by/ $4.0 /)$.

\begin{abstract}
The mixed traffic flow has an increasingly impact on the operation of urban traffic. To study the evolution law of multi-group behaviors in pedestrian crossing, we used the evolutionary game theory to establish a multi-group behavior evolution model for pedestrian crossing. The process of concern started from the risk perception and multi-group behavior choice. The evolutionary stability strategies, evolution trends, and factors affecting the evolutionary path of multi-group behaviors are discussed in this paper. This study found that evolutionary strategy equilibrium of pedestrians, drivers, and traffic managers not only relied on their own earning, but also on those of the other two groups. The factors affecting its behavior included the revenue factor and the limiting factor. Evolutionary game theory was used to analyze the multi-group interaction behavior of pedestrians, vehicle drivers, and traffic managers in the process of pedestrian crossing, as well as to analyze the behavior of traffic subjects in the process of pedestrian crossing. This paper provides a basis for decision-making for the traffic management department to manage road traffic, offering a new idea from the perspective of evolution for solving the conflict of interest at the crosswalk of the road section.
\end{abstract}

Keywords: multi-group behavior; pedestrian crossing; evolutionary game theory; behavioral evolution

\section{Introduction}

Traffic accidents involving pedestrians have long been a major safety concern all over the world, particularly in developing countries, due to high population density, rapid urbanization, and lack of adherence to traffic regulations by both drivers and pedestrians [1]. In view of the fact that traffic participants such as pedestrians, vehicle drivers, and traffic managers have a very important influence on the state of urban traffic, their behavior has become the focus of research at home and abroad. Previous studies were conducted from the perspectives of group behavior characteristics [2-6], behavioral simulation [7,8], and behavioral psychology [9] of pedestrians, vehicle drivers, and traffic managers.

In terms of group behavior characteristics, some existing studies have focused on the behavioral characteristics of certain types of people, including groups such as the elderly and children, men and women [10-17]. Some studies used the probability theory method combined with the survey data to explain the traffic engineering characteristics of traffic subject behavior [18,19]. There are also studies exploring the risk behaviors of road users [20-22] and reliability analysis of drivers in urban intersections [23]. However, at present, only the behavior characteristics of different groups of crossing pedestrians have been studied, which are not comprehensive, and there is limited research on the behavior characteristics of multi-group.

In terms of behavioral simulation, some existing studies have used fluid mechanics, dynamics [24,25], the theory of planned behavior (TPB) [26,27], cellular automaton models $[28,29]$, etc. to study the effects of pedestrians, vehicle drivers, and traffic managers on 
road traffic. These models and theories are capable of simulating the traffic participants characteristics, but they are unable to fully demonstrate the dynamic interaction between traffic participants and external environment. In terms of behavioral psychology, studies have used statistical analysis methods to explain the behavioral mechanisms of pedestrians, vehicle drivers, and traffic managers under the guidance of social psychology, traffic psychology, and cognitive psychology [30].

In the latest research on pedestrian crossings, empirical trajectory data are used to study the influence of pedestrian flow on path planning behavior in a certain spatial and temporal range [31]. On the basis of dynamic group decision theory of herd mentality, Xiao et al. [32] analyzed pedestrian violation mechanism and focused on the interaction views of pedestrian violation under the influence of herd mentality. The generalized estimation equation is used to construct a binary model of pedestrian crossing behavior, and the benefit of refuge island is evaluated [33]. Pedestrian crossings have been assessed from an operational perspective, wherein Hyung et al. [34] considered the conflict between pedestrians and driving vehicles, vehicle encounter, crossing time, and auditory perception as indicators. The dynamic decision model of pedestrian jaywalking is proposed on the basis of the extended decision field theory. The model links the perception of pedestrians in the three dimensions of efficiency, safety, and fairness with the dynamic traffic environment, and shows the evolution process of pedestrian decision-making [35].

Most of the existing literature are analyzed from the static perspective or the dynamic perspective of the two parties involved. Rarely has research been conducted on the three-party multi-group interaction behavior of pedestrians, vehicle drivers, and traffic management personnel in the process of pedestrian crossing. At the same time, for the evolution process and evolution law of traffic participants, the traditional traffic flow model, and theory are unable to explain the crossing mechanism sufficiently. The evolutionary game used in this paper can better analyze the evolution process, evolution law, and evolution path of traffic subject behavior in the process of pedestrian crossing from the perspective of evolution. On the basis of this, this paper based on evolutionary game theory took into account the time-revenue factors, security factors, and psychological factors in order to construct the payment matrix from the perspective of bounded rationality, and the behavior of the traffic participants were systematically modeled. On the basis of the equilibrium point analysis, we analyzed the evolution trend of the above traffic subject behavior. The behavioral development trend and the influencing factors of the evolution path were simulated by MATLAB. Additionally, the evolution path of crossing pedestrians and vehicle drivers' behavior are discussed.

The rest of this paper is organized as follows. Section 2 recurs the multi-group behavior interaction scenario and establishes an asymmetric behavior evolution model. Section 3 analyzes the behavior evolution trend and parameter sensitivity on the basis of the equilibrium point. Section 4 numerically simulates the evolution of multi-group behavior. The conclusions of this paper are presented in Section 5.

\section{Multi-Group Asymmetric Behavior Evolution Model}

\subsection{Scenario Recurrence and Hypothesis}

There are three pairs of gaming: gaming between government and traffic participants, gaming between traffic managers and traffic participants, and gaming between traffic participants. He et al. [36] believe that traffic managers aim to maximize social revenue, while traffic participants are tempered to maximize their own revenue. There are information asymmetry and conflicts between these two groups, which are in line with the premise and application conditions of game theory. In reality, pedestrians and vehicle drivers do not always follow the traffic rules, and traffic managers sometimes manage carelessly. In this case, there is room for gaming. This chapter analyzes pedestrians, traffic managers, and vehicle drivers on the basis of the main game mechanism of traffic participation.

To analyze the multi-group game of pedestrian crossing, we developed the cross-street scenario of this model as follows: at the intersection, there are traffic managers who are 
supervising and pedestrians who may violate the rules in order to save crossing time. Meanwhile, drivers also violate regulations due to profit-driven motives. Moreover, in the process of crossing, vehicles and pedestrians also have conflicts and disturbances due to competition for limited traffic resources. Traffic managers impose penalties on pedestrians and drivers because of their violation. In order to facilitate the establishment of the model, we made the following assumptions according to the characteristics of various traffic participants in urban traffic in China.

(1) Under the complicated traffic environment, there are three groups with learning adaptability in the process of pedestrian crossing: pedestrians, vehicle drivers, and traffic managers. The set of pedestrian behavior is Option $_{1}=\{$ violation, obeying traffic rules . The set of driver behavior is $\mathrm{Option}_{2}=\{$ violation, obeying traffic rules $\}$. The set of traffic manager behavior is $\mathrm{Option}_{3}=\{$ strict management, careless management $\}$.

(2) Obeying traffic rules will bring safety revenue to pedestrians, which is represented by $e_{2}$. Pedestrians will obtain certain time revenue in violation of traffic rules, which is represented by $e_{3}$. Pedestrians' compliance with traffic rules will result in a loss of time revenue, which is represented by $-e_{3}$. Violation of traffic rules will cause traffic accidents, and this loss is represented by $L_{1}$. The probability that a pedestrian violates the regulations and the driver does not violate but a traffic accident occurs is $p_{3}$.

(3) Effective traffic management will bring about certain revenue to traffic managers, which is represented by $e_{1}$. At the same time, careless management leads to traffic disorder and adverse effects on traffic patency, because the accountability of the superior department causes a certain loss to the traffic managers, which is represented by $D$. Meanwhile, the traffic management department has administrative law enforcement costs in the process of traffic management, and we assume that the cost of strict management is $C_{1}$.

(4) The vehicle drivers' compliance with the rules has a safety revenue, assuming that the safety revenue obtained by obeying traffic rules is $e_{5}$, with the loss of time revenue being indicated by $-e_{4}$. Meanwhile, it is assumed that the time revenue that drivers may obtain in violation of traffic rules is represented by $e_{4}$. When a vehicle driver violates regulations and causes a traffic accident occurs, the loss to the driver is $L_{2}$. Under the condition that the pedestrian does not violate the regulations but the drivers violate them, the probability of a traffic accident occurring is $p_{4}$. Under the condition that pedestrians and vehicles are all in violation of regulations, the probability of a traffic accident occurs is $p_{5}$.

(5) Assume that traffic managers manage strictly. Once pedestrians and vehicle drivers are found to be in violation of regulations, penalties will be imposed. The number of penalties imposed on pedestrians is $m$, and the number of penalties imposed on vehicle drivers is $M$. The probability of pedestrians' punishment under conditions of careless management is $p_{1}$. Moreover, the probability of vehicle drivers' punishment under conditions of careless management is $p_{2}$.

(6) Assume that the probability of strict management is $z$, and the probability of careless management is $1-z$. Suppose that the probability of pedestrians obeying traffic rules is $x$, and the probability of violation is $1-x$. Moreover, it is assumed that the probability of the vehicle driver complies with the traffic rules is $y$, and the probability of violation is $1-y$.

With reference to the above assumptions, we show the payoff matrix of multi-group game in the context of pedestrian crossing in Table 1.

\subsection{Multi-Group Behavior Evolution Dynamic Replication Equation}

Traffic participant behavior has subjective initiative and adaptability. In a complex traffic environment, traffic participants can search for rules and practices of the new environment, and crossing pedestrians can continue to evolve in this continuous search process. On the basis of this, the behavior evolution of traffic participants in this paper refers to the traffic subject constantly adjusting its own behavior and evolution path in 
order to adapt to the changes of the new environment. This leads to a series of changes in the state and characteristics of the traffic individual.

Table 1. The payoff matrix.

\begin{tabular}{|c|c|c|c|}
\hline \multicolumn{4}{|c|}{ The Payoff Matrix under Strict Management by Traffic Manager } \\
\hline & & \multicolumn{2}{|l|}{ Vehicle Driver } \\
\hline & & Violation & $\begin{array}{l}\text { Obeying Traffic } \\
\text { Rules }\end{array}$ \\
\hline \multirow[t]{2}{*}{ Pedestrian } & Violation & $\begin{array}{l}e_{3}-p_{5} L_{1}-m \\
e_{4}-p_{5} L_{2}-M, e_{1} C_{1}+ \\
m+M\end{array}$ & $\begin{array}{l}e_{3}-p_{3} L_{1}-m \\
e_{5}-e_{4}, e_{1}-C_{1}+m\end{array}$ \\
\hline & Obeying traffic rules & $\begin{array}{l}e_{2}-e_{3} \\
e_{4}-p_{4} L_{2}-M \\
e_{1}-C_{1}+M\end{array}$ & $\begin{array}{l}e_{2}-e_{3}, e_{5}-e_{4} \\
e_{1}-C_{1}\end{array}$ \\
\hline \multicolumn{4}{|c|}{ The Payoff Matrix under Careless Management by Traffic Manager } \\
\hline & & \multicolumn{2}{|l|}{ Vehicle Driver } \\
\hline & & Violation & $\begin{array}{l}\text { Obeying Traffic } \\
\text { Rules }\end{array}$ \\
\hline \multirow[t]{2}{*}{ Pedestrian } & Violation & $\begin{array}{l}e_{3}-p_{5} L_{1}-m p_{1} \\
e_{4}-p_{5} L_{2}- \\
M p_{2}, m p_{1}+M p_{2}-D\end{array}$ & $\begin{array}{l}e_{3}-p_{3} L_{1}-m p_{1} \\
e_{5}-e_{4}, m p_{1}-D\end{array}$ \\
\hline & Obeying traffic rules & $\begin{array}{l}e_{2}-e_{3} \\
e_{4}-p_{4} L_{2}-M p_{2} \\
M P_{2}-D\end{array}$ & $e_{2}-e_{3}, e_{5}-e_{4},-D$ \\
\hline
\end{tabular}

where $e_{1}$ : effective traffic management will bring certain revenue to traffic managers; $e_{2}$ : obeying traffic rules will bring safety revenue to pedestrians; $e_{3}:$ pedestrians will obtain certain time revenue in violation of traffic rules; $e_{4}$ : the time revenue that drivers may obtain in violation of traffic rules; $e_{5}$ : the safety revenue obtained by obeying traffic rules; $L_{1}$ : violation of traffic rules will cause traffic accidents; $L_{2}$ : the loss to the driver when a vehicle driver violates regulations and causes a traffic accident; $p_{1}$ : the probability of pedestrians' punishment under conditions of careless management; $p_{2}$ : the probability of vehicle drivers' punishment under conditions of careless management; $p_{3}$ : the probability that a pedestrian violates the regulations and the driver does not violate them but a traffic accident occurs; $p_{4}$ : the probability of a traffic accident occurring where the pedestrian did not violate the regulations but the driver violated them; $p_{5}$ : the probability of a traffic accident occurring in which pedestrians and vehicles were all in violation of regulations; $D$ : the accountability of the superior department causing a certain loss to the traffic managers; $C_{1}$ : the cost of strict management; $m$ : the amount of penalties imposed on pedestrians; $M$ : the amount of penalties imposed on vehicle drivers.

According to the behavior payoff matrix above, the expected revenue $U_{1}$ of the pedestrian violation, the expected revenue $U_{2}$ of obeying the traffic rules, and the average expected revenue $\bar{U}$ are as shown in Equations (1)-(3), respectively.

The expected revenue $V_{1}$ of vehicle drivers in violation of traffic rules, the expected revenue $V_{2}$ that obeying the traffic rules, and the average expected revenue $\bar{V}$ of vehicle drivers are shown in Equations (4)-(6), respectively.

In the same way, the expected revenue $W_{1}$ of strict management by traffic managers, the expected revenue $W_{2}$ of careless management, and the average expected revenue $\bar{W}$ of traffic managers are shown in Equations (7)-(9), respectively.

In accordance with the Malthusian dynamic replication equation, the dynamic replication equations for the behavior evolution of pedestrians, vehicle drivers, and traffic managers are shown in Equation (10).

$F(x, y, z), G(x, y, z)$, and $H(x, y, z)$ are separately derived to obtain a Jacobian matrix as shown in Equation (11).

From the dynamic replication equations of behavioral evolution of pedestrians, vehicle drivers, and traffic managers, it is known that when the revenue of a certain strategy $S$ is greater than the average revenue of the group, more individuals choose the strategy. When the revenue of the selected strategy $S$ is exactly equal to the average revenue of the group, the individual growth number of the selected strategy is zero. When the revenue of 
the selected strategy $S$ is less than the average revenue of the group, the individual growth number of the selected strategy is negative.

$$
\begin{aligned}
& U_{1}=(1-y) z\left(e_{3}-p_{5} L_{1}-m\right)+y z\left(e_{3}-p_{3} L_{1}-m\right)+(1-y)(1-z)\left(e_{3}-p_{5} L_{1}-m p_{1}\right)+y(1-z)\left(e_{3}-p_{3} L_{1}-m p_{1}\right) \\
& U_{2}=(1-y) z\left(e_{2}-e_{3}\right)+y z\left(e_{2}-e_{3}\right)+(1-y)(1-z)\left(e_{2}-e_{3}\right)+y(1-z)\left(e_{2}-e_{3}\right)=\left(e_{2}-e_{3}\right) \\
& \bar{U}=x U_{2}+(1-x) U_{1} \\
& V_{1}=(1-x) z\left(e_{4}-p_{5} L_{2}-M\right)+x z\left(e_{4}-p_{4} L_{2}-M\right)+(1-x)(1-z)\left(e_{4}-p_{5} L_{2}-M p_{2}\right)+x(1-z)\left(e_{4}-p_{4} L_{2}-M p_{2}\right) \\
& V_{2}=(1-x) z\left(e_{5}-e_{4}\right)+x z\left(e_{5}-e_{4}\right)+(1-x)(1-z)\left(e_{5}-e_{4}\right)+x(1-z)\left(e_{5}-e_{4}\right) \\
& \bar{V}=y V_{2}+(1-y) V_{1} \\
& W_{1}=e_{1}-C_{1}+m+M-m x-M y \\
& W_{2}=m p_{1}+M p_{2}-D-m p_{1} x-M p_{2} y \\
& \bar{W}=z W_{1}+(1-z) W_{2} \\
& \left\{\begin{array}{c}
F(x, y, z)=x(1-x)\left[e_{2}-2 e_{3}+z\left(m-m p_{1}\right)-y L_{1}\left(p_{5}-p_{3}\right)+p_{5} L_{1}+m p_{1}\right] \\
G(x, y, z)=y(1-y)\left[e_{5}-2 e_{4}+z\left(M-M p_{2}\right)-x L_{2}\left(p_{5}-p_{4}\right)+p_{5} L_{2}+M p_{2}\right] \\
H(x, y, z)=z(1-z)\left[e_{1}-C_{1}+\left(m-m p_{1}\right)(1-x)+\left(M-M p_{2}\right)(1-y)+D\right]
\end{array}\right. \\
& (1-2 x)\left[e_{2}-2 e_{3}+z\left(m-m p_{1}\right)-y L_{1}\left(p_{5}-p_{3}\right)+p_{5} L_{1}+m p_{1}\right],-x(1-x) L_{1}\left(p_{5}-p_{3}\right), x(1-x)\left(m-m p_{1}\right) \\
& -y(1-y)\left(p_{5}-p_{4}\right) L_{2},(1-2 y)\left[e_{5}-2 e_{4}+z\left(M-M p_{2}\right)-x\left(p_{5}-p_{4}\right) L_{2}+p_{5} L_{2}+M p_{2}\right], y(1-y)\left(M-M p_{2}\right) \\
& \left.-z(1-z)\left(m-m p_{1}\right),-z(1-z)\left(M-M p_{2}\right),(1-2 z)\left[e_{1}-C_{1}+\left(m-m p_{1}\right)(1-x)+\left(M-M p_{2}\right)(1-y)+D\right]\right] \\
& \text { where } \\
& U_{1} \text { : The expected revenue of the pedestrian violation; } \\
& U_{2} \text { : The expected revenue of obeying the traffic rules; } \\
& \bar{U} \text { : The average expected revenue; } \\
& V_{1} \text { : The expected revenue of vehicle drivers in violation of traffic rules; } \\
& V_{2} \text { : The expected revenue of obeying the traffic rules; } \\
& \bar{V} \text { : The average expected revenue of vehicle drivers; } \\
& W_{1} \text { : The expected revenue of strict management by traffic managers; } \\
& W_{2} \text { : The expected revenue of careless management; } \\
& \bar{W} \text { : The average expected revenue of traffic managers; } \\
& x \text { : The probability of pedestrians obeying traffic rules; } \\
& y \text { : The probability of the vehicle driver complies with the traffic rules; } \\
& z \text { : The probability of strict management. }
\end{aligned}
$$

\section{Multi-Group Behavior Evolution and Stability Analysis}

\subsection{Analysis of Behavior Evolution Trend Based on Equilibrium Point}

On the plane $B=\{(x, y, z) / 0 \leq x, y, z \leq 1\}$, let the differential equations \{ $F(x, y, z)=0$

$G(x, y, z)=0$, and the solutions of the third-order differential equations can be ob$H(x, y, z)=0$

tained as shown in Equations (12)-(14).

Among them, for the convenience of solving, the following equations are defined: $\lambda_{1}=m-m p_{1}, \lambda_{2}=L_{1}\left(p_{5}-p_{3}\right), \lambda_{3}=e_{2}-2 e_{3}+p_{5} L_{1}+m p_{1}, \varphi_{1}=M-M p_{2}$, $\varphi_{2}=L_{2}\left(p_{5}-p_{4}\right), \varphi_{3}=e_{5}-2 e_{4}+p_{5} L_{2}+M p_{2}, \sigma_{3}=e_{1}-C_{1}+D$.

If the evolutionary game equilibrium is a gradual steady state, it must be a strict Nash equilibrium. While the strict Nash equilibrium is a purely strategic Nash equilibrium, it is only necessary to discuss points of $(0,0,0),(1,0,0),(0,1,0),(0,0,1),(1,1,0)$, $(1,0,1),(0,1,1)$, and $(1,1,1)$ for the dynamic replication system of Equations (12)-(14). Obviously, these eight points are the balance points of the dynamic replication system, which correspond to an evolutionary game equilibrium. Meanwhile, in order to make the traffic participants revenue closer to the actual traffic situation, it is necessary to increase the constraint conditions. For crossing pedestrians and vehicle drivers, they are motivated to violate the regulations under the condition that traffic managers manage carelessly. 
Therefore, it is reasonable to assume that the revenue of violations of pedestrians and vehicle drivers are greater than the revenue of obeying the rules. For traffic managers, under the conditions of pedestrians and vehicle drivers who violate the rules, the revenue of their strict management is greater than the revenue of careless management. At this time, there are constraints as shown in Equation (15) for pedestrians, vehicle drivers, and traffic managers.

According to the second method of Lyapunov stability, the stability of the equilibrium point can be judged as shown in Table 2.

$$
\begin{gathered}
x=0, x=1, x^{*}=\frac{\lambda_{2}\left(\lambda_{1}+\varphi_{1}+\sigma_{3}\right)+\lambda_{1} \varphi_{3}-\lambda_{3} \varphi_{1}}{\lambda_{1}\left(\lambda_{2}+\varphi_{2}\right)} \\
y=0, y=1, y^{*}=\frac{\varphi_{2}\left(\lambda_{1}+\varphi_{1}+\sigma_{3}\right)+\lambda_{3} \varphi_{1}-\lambda_{1} \varphi_{3}}{\varphi_{1}\left(\lambda_{2}+\varphi_{2}\right)} \\
z=0, z=1, z^{*}=\frac{\lambda_{2} \varphi_{2}\left(\lambda_{1}+\varphi_{1}+\sigma_{3}\right)-\lambda_{1} \lambda_{2} \varphi_{3}-\lambda_{3} \varphi_{1} \varphi_{2}}{\lambda_{1} \varphi_{1}\left(\lambda_{2}+\varphi_{2}\right)} \\
2 e_{3}-e_{2}-p_{5} L_{1}-m p_{1}>0,2 e_{4}-e_{5}-p_{5} L_{2}-M p_{2}>0, e_{1}-C_{1}+D>0
\end{gathered}
$$

\begin{tabular}{|c|c|c|}
\hline Equilibrium Point & Jacobian Matrix Eigenvalues & Result \\
\hline$(0,0,0)$ & $\begin{array}{l}e_{2}-2 e_{3}+p_{5} L 1+m p_{1}<0 \\
e_{5}-2 e_{4}+p_{5} L_{2}+M p_{2}<0 \\
e_{1}-C_{1}+m+M-m p_{1}- \\
M p_{2}+D>0\end{array}$ & Unstable \\
\hline$(1,0,0)$ & $\begin{array}{l}2 e_{3}-e_{2}-p_{5} L 1-m p_{1}>0 \\
e_{5}-2 e_{4}+p_{4} L 2+M p_{2}<0 \\
e_{1}-C_{1}+M-M p_{2}+D>0\end{array}$ & Unstable \\
\hline$(0,1,0)$ & $\begin{array}{l}e_{2}-2 e_{3}+p_{3} L 1+m p_{1}<0 \\
2 e_{4}-e_{5}-p_{5} L 2-M p_{2}>0 \\
e_{1}-C_{1}+m-m p_{1}+D>0\end{array}$ & Unstable \\
\hline$(0,0,1)$ & $\begin{array}{l}e_{2}-2 e_{3}+p_{5} L 1+m<0 \\
e_{5}-2 e_{4}+p_{5} L 2+M<0 \\
C_{1}-e_{1}-m-M+m p_{1}+ \\
M p_{2}-D<0\end{array}$ & Stable \\
\hline$(1,1,0)$ & $\begin{array}{l}2 e_{3}-e_{2}-p_{3} L_{1}-m p_{1}>0 \\
2 e_{4}-e_{5}-p_{4} L 2-M p_{2}>0 \\
e_{1}-C_{1}+D>0\end{array}$ & Unstable \\
\hline$(1,0,1)$ & $\begin{array}{l}2 e_{3}-e_{2}-p_{5} L 1-m>0 \\
e_{5}-2 e_{4}+M+p_{4} L_{2}<0 \\
C_{1}-e_{1}-M+M p_{2}-D<0\end{array}$ & Unstable \\
\hline$(0,1,1)$ & $\begin{array}{l}e_{2}-2 e_{3}+p_{3} L_{1}+m<0 \\
2 e_{4}-e_{5}-M-p_{5} L_{2}>0 \\
C_{1}-e_{1}-m+m p_{1}-D<0\end{array}$ & Unstable \\
\hline$(1,1,1)$ & $\begin{array}{l}2 e_{3}-e_{2}-p_{3} L_{1}-m>0 \\
2 e_{4}-e_{5}-M-p_{4} L_{2}>0\end{array}$ & Unstable \\
\hline
\end{tabular}

Table 2. Measurement conversion.

It can be seen from Table 2 that the system has a global unique stable equilibrium point $(0,0,1)$, and the corresponding behavior strategies of traffic subject are crossing pedestrian violation, vehicle driver violation, and traffic manager strict management. It is an evolutionary stability strategy under current conditions. When crossing pedestrians and vehicle drivers violate with $x^{*}$ and $y^{*}$, and the traffic managers manage with $z^{*}$, the hybrid strategy Nash equilibrium state is reached between the vehicle driver, the crossing pedestrian, and the traffic manager. By analyzing the mixed strategy Nash equilibrium, 
the probability of strict management of traffic manager can be obtained. Meanwhile, vehicle drivers and crossing pedestrians have adopted the most favorable strategy for themselves in order to obtain greater revenue. As a result, they all receive sub-optimal revenue and fail to maximize total revenue and self-revenue.

\subsection{Sensitivity Analysis}

Sensitivity analysis is conducted to analyze the influence of various parameters on behavioral evolution. This section uses the derivation method to analyze the impact of parameters on behavior.

(1) The impact of $C_{1}$ on behavioral evolution. The following equations exist at the center point:

$$
\begin{gathered}
\frac{\partial x^{*}}{\partial C_{1}}=-\frac{L_{1}\left(p_{5}-p_{3}\right)}{\left(m-m p_{1}\right)\left[L_{1}\left(p_{5}-p_{3}\right)+L_{2}\left(p_{5}-p_{4}\right)\right]}<0 \\
\frac{\partial y^{*}}{\partial C_{1}}=-\frac{L_{2}\left(p_{5}-p_{4}\right)}{\left(M-M p_{2}\right)\left[L_{1}\left(p_{5}-p_{3}\right)+L_{2}\left(p_{5}-p_{4}\right)\right]}<0 \\
\frac{\partial z^{*}}{\partial C_{1}}=-\frac{L_{1}\left(p_{5}-p_{3}\right) L_{2}\left(p_{5}-p_{4}\right)}{\left(m-m p_{1}\right)\left(M-M p_{2}\right)\left[L_{1}\left(p_{5}-p_{3}\right)+L_{2}\left(p_{5}-p_{4}\right)\right]}<0
\end{gathered}
$$

The increase of $C_{1}$ has a negative impact on the crossing pedestrians and vehicle drivers obeying the rules, and has a negative impact on the strict management behavior of traffic manager. Meanwhile, it increases the probability that the system converges toward the point of $(0,0,0)$.

(2) The impact of $L_{1}$ on the evolution of behavior. The following equations exist at the center point:

$$
\begin{gathered}
\frac{\partial x^{*}}{\partial L_{1}}=\frac{\left[\left(p_{5}-p_{3}\right)\left(\lambda_{1}+\varphi_{1}+\sigma_{3}\right)-p_{5} \varphi_{1}\right] \lambda_{1}\left(\lambda_{2}+\varphi_{2}\right)-\left[\lambda_{2}\left(\lambda_{1}+\varphi_{1}+\sigma_{3}\right)+\lambda_{1} \varphi_{3}-\lambda_{3} \varphi_{1}\right] \lambda_{1}\left(p_{5}-p_{3}\right)}{\lambda_{1}^{2}\left(\lambda_{2}+\varphi_{2}\right)^{2}}>0 \\
\frac{\partial y^{*}}{\partial L_{1}}=\frac{p_{5}\left(\lambda_{2}+\varphi_{2}\right) \varphi_{1}^{2}-\left(p_{5}-p_{3}\right) \varphi_{1}\left[\varphi_{2}\left(\lambda_{1}+\varphi_{1}+\sigma_{3}\right)+\lambda_{3} \varphi_{1}-\lambda_{1} \varphi_{3}\right]}{\lambda_{1}^{2}\left(\lambda_{2}+\varphi_{2}\right)^{2}}>0 \\
\frac{\partial z^{*}}{\partial L_{1}}=\frac{\left[\left(p_{5}-p_{3}\right) \varphi_{2}\left(\lambda_{1}+\varphi_{1}+\sigma_{3}\right)-\left(p_{5}-p_{3}\right) \lambda_{1} \varphi_{3}-p_{5} \varphi_{1} \varphi_{2}\right] \lambda_{1} \varphi_{1}\left(\lambda_{2}+\varphi_{2}\right)-\left[\lambda_{2} \varphi_{2}\left(\lambda_{1}+\varphi_{1}+\sigma_{3}\right)-\lambda_{1} \lambda_{2} \varphi_{3}-\lambda_{3} \varphi_{1} \varphi_{2}\right] \lambda_{1} \varphi_{1}\left(p_{5}-p_{3}\right)}{\lambda_{1}^{2} \varphi_{1}^{2}\left(\lambda_{2}+\varphi_{2}\right)^{2}}
\end{gathered}
$$

$L_{1}$ has a positive impact on the behavior of vehicle drivers and crossing pedestrians obeying the rules, and the impact on the behavior of traffic manager is uncertain.

(3) The impact of $p_{3}$ on the evolution of the system. The following equations exist at the center point:

$$
\begin{gathered}
\frac{\partial x^{*}}{\partial p_{3}}=\frac{-L_{1}\left(\lambda_{1}+\varphi_{1}+\sigma_{3}\right) \lambda_{1}\left(\lambda_{2}+\varphi_{2}\right)+\left[\lambda_{2}\left(\lambda_{1}+\varphi_{1}+C_{3}\right)+\lambda_{1} \varphi_{3}-\lambda_{3} \varphi_{1}\right] L_{1} \lambda_{1}}{\lambda_{1}^{2}\left(\lambda_{2}+\varphi_{2}\right)^{2}}>0 \\
\frac{\partial y^{*}}{\partial p_{3}}=\frac{\left[\varphi_{2}\left(\lambda_{1}+\varphi_{1}+\sigma_{3}\right)+\lambda_{1} \varphi_{3}-\lambda_{3} \varphi_{1}\right] L_{1}}{\varphi_{1}^{2}\left(\lambda_{2}+\varphi_{2}\right)^{2}}>0 \\
\frac{\partial z^{*}}{\partial p_{3}}=\frac{\left[-L_{1} \varphi_{2}\left(\lambda_{1}+\varphi_{1}+\sigma_{3}\right)+L_{1} \lambda_{1} \varphi_{3}\right] \lambda_{1} \varphi_{1}\left(\lambda_{2}+\varphi_{2}\right)+\left[\lambda_{2} \varphi_{2}\left(\lambda_{1}+\varphi_{1}+\sigma_{3}\right)-\lambda_{1} \lambda_{2} \varphi_{3}-\lambda_{3} \varphi_{1} \varphi_{2}\right] \lambda_{1} \varphi_{1} L_{1}}{\lambda_{1}^{2} \varphi_{1}^{2}\left(\lambda_{2}+\varphi_{2}\right)^{2}}
\end{gathered}
$$

$p_{3}$ has a positive impact on the behavior of the vehicle driver and crossing pedestrian obeying the rules, and the impact on the behavior of the traffic manager is uncertain.

(4) The impact of $L_{2}$ on the evolution of the system. The following equations exist at the center point:

$$
\frac{\partial x^{*}}{\partial L_{2}}=\frac{p_{5} \lambda_{1}^{2}\left(\lambda_{2}+\varphi_{2}\right)-\left[\lambda_{2}\left(\lambda_{1}+\varphi_{1}+\sigma_{3}\right)+\lambda_{1} \varphi_{3}-\lambda_{3} \varphi_{1}\right] \lambda_{1}\left(p_{5}-p_{4}\right)}{\lambda_{1}^{2}\left(\lambda_{2}+\varphi_{2}\right)^{2}}>0
$$




$$
\begin{gathered}
\frac{\partial y^{*}}{\partial L_{2}}=\frac{\left[\left(p_{5}-p_{4}\right)\left(\lambda_{1}+\varphi_{1}+\sigma_{3}\right)-p_{5} \lambda_{1}\right] \varphi_{1}\left(\lambda_{2}+\varphi_{2}\right)-\left[\varphi_{2}\left(\lambda_{1}+\varphi_{1}+\sigma_{3}\right)+\lambda_{3} \varphi_{1}-\lambda_{1} \varphi_{3}\right] \varphi_{1}\left(p_{5}-p_{4}\right)}{\varphi_{1}^{2}\left(\lambda_{2}+\varphi_{2}\right)^{2}}>0 \\
\frac{\partial z^{*}}{\partial L_{2}}=\frac{\left[\left(p_{5}-p_{4}\right) \lambda_{2}\left(\lambda_{1}+\varphi_{1}+\sigma_{3}\right)-\left(p_{5}-p_{4}\right) \lambda_{3} \varphi_{1}-p_{5} \lambda_{1} \lambda_{2}\right] \lambda_{1} \varphi_{1}\left(\lambda_{2}+\varphi_{2}\right)-\left[\lambda_{2} \varphi_{2}\left(\lambda_{1}+\varphi_{1}+\sigma_{3}\right)-\lambda_{1} \lambda_{2} \varphi_{3}-\lambda_{3} \varphi_{1} \varphi_{2}\right] \lambda_{1} \varphi_{1}\left(p_{5}-p_{4}\right)}{\lambda_{1}^{2} \varphi_{1}^{2}\left(\lambda_{2}+\varphi_{2}\right)^{2}}
\end{gathered}
$$

$L_{2}$ has a positive impact on the behavior of crossing pedestrians and vehicle drivers obeying the rules, and the impact on the behavior of traffic manager is uncertain.

(5) The impact of $M$ on the evolution of the system. The following equations exist at the center point:

$$
\begin{gathered}
\frac{\partial x^{*}}{\partial M}=\frac{\left(1-p_{1}\right)\left(\lambda_{2}-\lambda_{3}\right)+p_{2} \lambda_{1}}{\lambda_{1}^{2}\left(\lambda_{2}+\varphi_{2}\right)^{2}}>0 \\
\frac{\partial y^{*}}{\partial M}=\frac{\left[\left(1-p_{2}\right)\left(\varphi_{2}+\lambda_{3}\right)-p_{2} \lambda_{1}\right] \varphi_{1}\left(\lambda_{2}+\varphi_{2}\right)-\left[\varphi_{2}\left(\lambda_{1}+\varphi_{1}+\sigma_{3}\right)+\lambda_{3} \varphi_{1}-\lambda_{1} \varphi_{3}\right]\left(1-p_{2}\right)\left(\lambda_{2}+\varphi_{2}\right)}{\varphi_{1}^{2}\left(\lambda_{2}+\varphi_{2}\right)^{2}}>0 \\
\frac{\partial z^{*}}{\partial M}=\frac{\left[\left(1-p_{2}\right) \lambda_{2} \varphi_{2}-p_{2} \lambda_{1} \lambda_{2}-\left(1-p_{2}\right) \lambda_{3} \varphi_{2}\right] \lambda_{1} \varphi_{1}\left(\lambda_{2}+\varphi_{2}\right)-\left[\lambda_{2} \varphi_{2}\left(\lambda_{1}+\varphi_{1}+\sigma_{3}\right)-\lambda_{1} \lambda_{2} \varphi_{3}-\lambda_{3} \varphi_{1} \varphi_{2}\right]\left(1-p_{2}\right) \lambda_{1}\left(\lambda_{2}+\varphi_{2}\right)}{\lambda_{1}^{2} \varphi_{1}^{2}\left(\lambda_{2}+\varphi_{2}\right)^{2}}
\end{gathered}
$$

$M$ has a positive impact on the behavior of crossing pedestrians and vehicle drivers obeying the rules, and the impact on the behavior of traffic manager is uncertain.

(6) The impact of $e_{1}$ on the evolution of the system. The following equations exist at the center point:

$$
\begin{gathered}
\frac{\partial x^{*}}{\partial e_{1}}=\frac{L_{1}\left(p_{5}-p_{3}\right)}{\left(m-m p_{1}\right)\left[L_{1}\left(p_{5}-p_{3}\right)+L_{2}\left(p_{5}-p_{4}\right)\right]}>0 \\
\frac{\partial y^{*}}{\partial e_{1}}=\frac{L_{2}\left(p_{5}-p_{4}\right)}{\left(M-M p_{2}\right)\left[L_{1}\left(p_{5}-p_{3}\right)+L_{2}\left(p_{5}-p_{4}\right)\right]}>0 \\
\frac{\partial z^{*}}{\partial e_{1}}=\frac{L_{1}\left(p_{5}-p_{3}\right) L_{2}\left(p_{5}-p_{4}\right)}{\left(m-m p_{1}\right)\left(M-M p_{2}\right)\left[L_{1}\left(p_{5}-p_{3}\right)+L_{2}\left(p_{5}-p_{4}\right)\right]}>0
\end{gathered}
$$

$e_{1}$ not only have an impact on the strict management behavior of traffic managers, but also have an impact on pedestrians and vehicle drivers obeying traffic rules, and their impact is positively correlated.

(7) The impact of $p_{5}$ on the evolution of the system. The following equations exist at the center point:

$$
\begin{aligned}
\frac{\partial x^{*}}{\partial p_{5}} & =\frac{\left[L_{1}\left(\lambda_{1}+\varphi_{1}+\sigma_{3}\right)+\lambda_{1} L_{2}-L_{1} \varphi_{1}\right] \lambda_{1}\left(\lambda_{2}+\varphi_{2}\right)-\left[\lambda_{2}\left(\lambda_{1}+\varphi_{1}+\sigma_{3}\right)+\lambda_{1} \varphi_{3}-\lambda_{3} \varphi_{1}\right] \lambda_{1}\left(L_{1}+L_{2}\right)}{\lambda_{1}^{2}\left(\lambda_{2}+\varphi_{2}\right)^{2}}>0 \\
\frac{\partial y^{*}}{\partial p_{5}} & =\frac{\left[L_{2}\left(\lambda_{1}+\varphi_{1}+\sigma_{3}\right)+L_{1} \varphi_{1}-\lambda_{1} L_{2}\right] \varphi_{1}\left(\lambda_{2}+\varphi_{2}\right)-\left[\varphi_{2}\left(\lambda_{1}+\varphi_{1}+\sigma_{3}\right)+\lambda_{3} \varphi_{1}-\lambda_{1} \varphi_{3}\right] \varphi_{1}\left(L_{1}+L_{2}\right)}{\varphi_{1}^{2}\left(\lambda_{2}+\varphi_{2}\right)^{2}}>0 \\
\frac{\partial z^{*}}{\partial p_{5}} & =\frac{\left[\left(L_{1} \varphi_{2}+L_{2} \lambda_{2}\right)\left(\lambda_{1}+\varphi_{1}+\sigma_{3}\right)-\lambda_{1}\left(L_{1} \varphi_{3}+L_{2} \lambda_{2}\right)-\varphi_{1}\left(L_{1} \varphi_{2}+L_{2} \lambda_{3}\right)\right] \lambda_{1} \varphi_{1}\left(\lambda_{2}+\varphi_{2}\right)-\left[\lambda_{2} \varphi_{2}\left(\lambda_{1}+\varphi_{1}+\sigma_{3}\right)-\lambda_{1} \lambda_{2} \varphi_{3}-\lambda_{3} \varphi_{1} \varphi_{2}\right] \lambda_{1} \varphi_{1}\left(L_{1}+L_{2}\right)}{\lambda_{1}^{2} \varphi_{1}^{2}\left(\lambda_{2}+\varphi_{2}\right)^{2}}
\end{aligned}
$$

$p_{5}$ has a positive impact on the behavior of the vehicle driver and crossing pedestrian obeying the rules, and the impact on the behavior of the traffic manager is uncertain.

(8) The impact of $e_{3}$ on the evolution of the system. The following equations exist at the center point:

$$
\begin{gathered}
\frac{\partial x^{*}}{\partial e_{3}}=-\frac{2 \varphi_{1}}{\lambda_{1}\left(\lambda_{2}+\varphi_{2}\right)}<0 \\
\frac{\partial y^{*}}{\partial e_{3}}=\frac{2 \varphi_{1}}{\varphi_{1}\left(\lambda_{2}+\varphi_{2}\right)}>0
\end{gathered}
$$




$$
\frac{\partial z^{*}}{\partial e_{3}}=\frac{2 \varphi_{1} \varphi_{2}}{\lambda_{1} \varphi_{1}\left(\lambda_{2}+\varphi_{2}\right)}>0
$$

$e_{3}$ have a negative impact on the pedestrians' compliance with the rules, and have a positive impact on the vehicle drivers' compliance with the rules and the traffic managers' strict management behavior.

In summary, through the sensitivity analysis of the parameters, we find that the behavioral factors affecting the traffic participants include the revenue factor and the limiting factor, and the evolution process of the traffic subject behavior is completed under the role of two factors. The revenue factors and limiting factors for the behavior of pedestrians, vehicle drivers, and traffic managers are as follows:

(1) The revenue factors of pedestrians to abide by traffic rules are as follows: $L_{1}, p_{3}$, $L_{2}, M, p_{5}$, and $e_{1}$. The limiting factors for pedestrians to abide by traffic rules are $C_{1}$ and $e_{3}$.

(2) The revenue factors of vehicle drivers to abide by traffic rules are as follows: $L_{1}, p_{3}$, $L_{2}, M, p_{5}$, and $e_{3}$. The limiting factor for vehicle drivers to abide by traffic rules is $C_{1}$.

(3) The revenue factors of traffic managers manage strictly are $e_{3}$ and $e_{1}$. The limiting factors of traffic managers management strictly are as follows: $C_{1}, e_{2}$, and $e_{5}$.

\section{Numerical Simulation of Multi-Group Behavior Evolution}

\subsection{Behavioral Dynamic Evolution Graph}

From the above theoretical analysis, we find that pedestrians, vehicle drivers, and traffic managers have different evolutionary trends. For different evolutionary trends, this section uses numerical simulation experiments to visually show the behavioral evolution of pedestrians, vehicle drivers, and traffic managers.

According to Equation (10), MATLAB is used for programming. The behavior of crossing pedestrians, vehicle drivers, and traffic managers are simulated under the parameters of Table 3 (Figure 1). Table 3 sets four initial conditions:

- Condition 1: pedestrians and vehicle drivers do not obey traffic rules and traffic managers carefully manage;

- Condition 2: pedestrians choose to obey the traffic rules, vehicle drivers do not obey the traffic rules, traffic managers do not carefully manage;

- Condition 3: pedestrians choose to obey the traffic rules, vehicle drivers do not obey the traffic rules, and traffic managers carefully manage;

- Condition 4: pedestrians choose to violate regulations, vehicle drivers abide by traffic rules, and traffic managers do not seriously manage.

Table 3. Simulation parameter settings.

\begin{tabular}{|c|c|c|c|c|c|}
\hline \multirow[t]{3}{*}{ Parameter } & \multirow[t]{3}{*}{ Symbol } & \multicolumn{4}{|c|}{ Conditions and Values } \\
\hline & & Condition 1 & Condition 2 & Condition 3 & Condition 4 \\
\hline & & $\begin{array}{l}e_{2}-2 e_{3}+p_{5} L 1+ \\
m<0 \\
e_{5}-2 e_{4}+p_{5} L 2+ \\
M<0 \\
C_{1}-e_{1}-m-M+ \\
m p_{1}+M p_{2}-D<0\end{array}$ & $\begin{array}{l}e_{2}-2 e_{3}+p_{5} L 1+ \\
m>0 \\
e_{5}-2 e_{4}+p_{5} L 2+ \\
M>0 \\
C_{1}-e_{1}-m-M+ \\
m p_{1}+M p_{2}-D>0\end{array}$ & $\begin{array}{l}e_{2}-2 e_{3}+p_{5} L 1+ \\
m>0 \\
e_{5}-2 e_{4}+p_{5} L 2+ \\
M<0 \\
C_{1}-e_{1}-m-M+ \\
m p_{1}+M p_{2}-D<0\end{array}$ & $\begin{array}{l}e_{2}-2 e_{3}+p_{5} L 1+ \\
m<0 \\
e_{5}-2 e_{4}+p_{5} L 2+ \\
M>0 \\
C_{1}-e_{1}-m-M+ \\
m p_{1}+M p_{2}-D>0\end{array}$ \\
\hline $\begin{array}{l}\text { Safety revenue of } \\
\text { obeying rules } \\
\text { to pedestrians }\end{array}$ & $e_{2}$ & 2 & 10 & 10 & 4 \\
\hline $\begin{array}{l}\text { Time revenue of } \\
\text { violation } \\
\text { to pedestrians }\end{array}$ & $e_{3}$ & 9 & 10 & 5 & 15 \\
\hline $\begin{array}{l}\text { Probability of a } \\
\text { traffic accident } \\
\text { occurring when } \\
\text { pedestrians and } \\
\text { vehicle drivers are } \\
\text { in violation }\end{array}$ & $p_{5}$ & 0.015 & 0.015 & 0.015 & 0.015 \\
\hline
\end{tabular}


Table 3. Cont

\begin{tabular}{|c|c|c|c|c|c|}
\hline Parameter & Symbol & Conc & & & \\
\hline $\begin{array}{l}\text { Loss to pedestrians } \\
\text { because of } \\
\text { traffic accident }\end{array}$ & $L_{1}$ & 200 & 200 & 200 & 200 \\
\hline $\begin{array}{l}\text { The amount of } \\
\text { penalty imposed on } \\
\text { a pedestrian }\end{array}$ & $m$ & 10 & 20 & 20 & 10 \\
\hline $\begin{array}{l}\text { Safety revenue of } \\
\text { obeying rules to } \\
\text { vehicle drivers }\end{array}$ & $e_{5}$ & 6 & 6 & 8 & 6 \\
\hline $\begin{array}{l}\text { Loss to of vehicle } \\
\text { drivers because of } \\
\text { obeying rules }\end{array}$ & $-e_{4}$ & -21 & -15 & -25 & -10 \\
\hline $\begin{array}{l}\text { Loss to vehicle } \\
\text { drivers because of } \\
\text { traffic accidents }\end{array}$ & $L_{2}$ & 300 & 500 & 300 & 500 \\
\hline $\begin{array}{l}\text { The amount of } \\
\text { penalty imposed on } \\
\text { a vehicle driver }\end{array}$ & $M$ & 30 & 40 & 30 & 40 \\
\hline $\begin{array}{l}\text { Cost of traffic } \\
\text { management }\end{array}$ & $C_{1}$ & 40 & 50 & 70 & 50 \\
\hline $\begin{array}{l}\text { Certain revenue of } \\
\text { effective traffic } \\
\text { management to } \\
\text { traffic managers }\end{array}$ & $e_{1}$ & 30 & 20 & 50 & 10 \\
\hline $\begin{array}{l}\text { Loss to the traffic } \\
\text { managers because of } \\
\text { the accountability of } \\
\text { the } \\
\text { superior department }\end{array}$ & $D$ & 15 & 15 & 15 & 12 \\
\hline $\begin{array}{l}\text { Pedestrian's } \\
\text { punishment } \\
\text { probability under } \\
\text { careless } \\
\text { management by } \\
\text { traffic managers }\end{array}$ & $p_{1}$ & 0.3 & 0.4 & 0.3 & 0.3 \\
\hline $\begin{array}{l}\text { Vehicle driver's } \\
\text { punishment } \\
\text { probability under } \\
\text { careless } \\
\text { management by } \\
\text { traffic managers }\end{array}$ & $p_{2}$ & 0.6 & 0.7 & 0.6 & 0.6 \\
\hline
\end{tabular}

Curves B11, B12, and B13 simulate the evolutionary trend of condition 1. As shown in B11 in Figure 1, after T $=227$ evolutions runs, the proportion of pedestrians obeying the rules evolved from the initial 0.7 to 0 , and the crossing pedestrians all evolved into risk violation of the crowd. Similar to the crossing pedestrians, the behavior of vehicle drivers no longer obeyed traffic rules after $\mathrm{T}=473$ times evolutions. After $\mathrm{T}=52$ times evolutions, the proportion of traffic managers' management also strictly evolved from the initial 0.5 to 1 . That is, the global unique stable equilibrium point was $(0,0,1)$. 


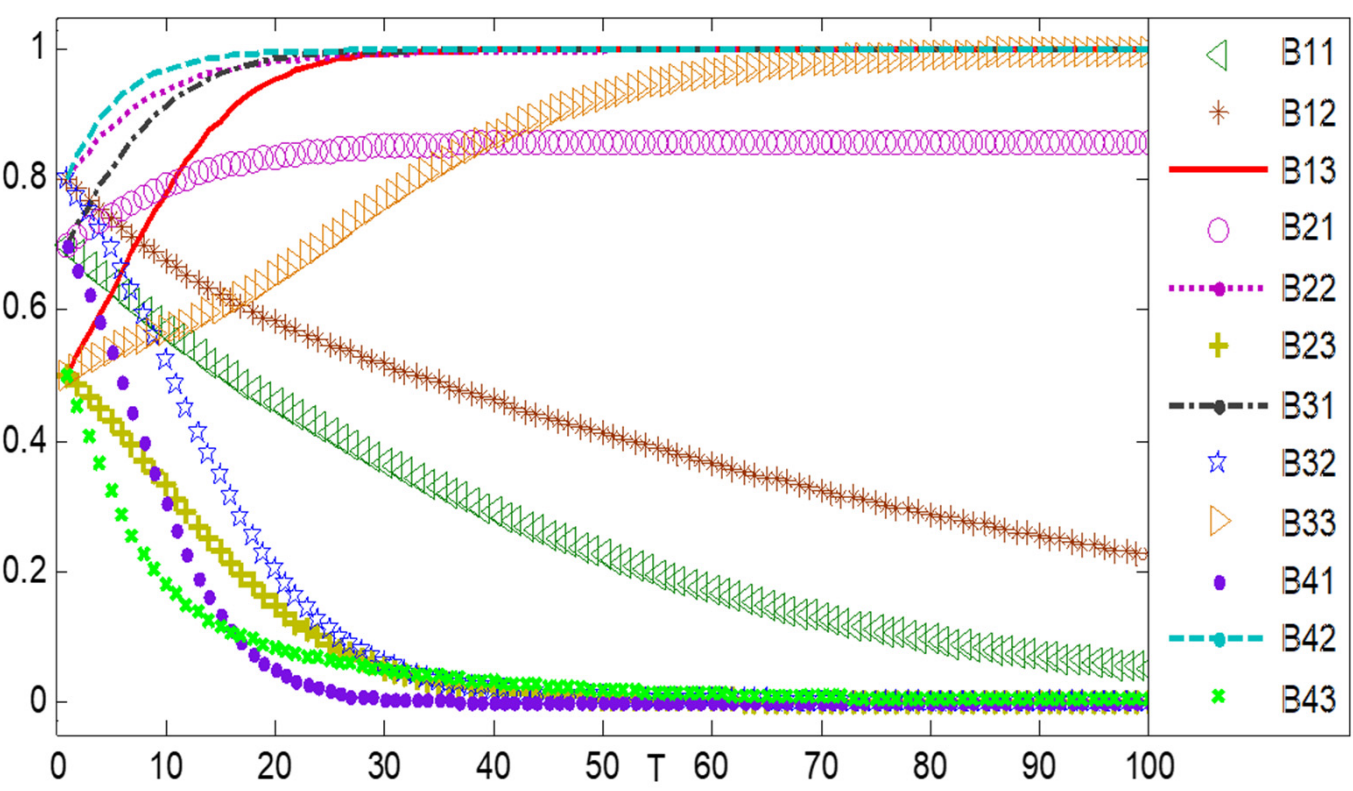

Figure 1. Behavior simulation of different conditions.

Curves B21, B22, and B23 simulated the evolutionary trend of condition 2. In Figure 1, the proportion of pedestrians obeying the rules gradually evolved from the beginning of 0.7 and eventually remained at 0.8583 , and the proportion of vehicle drivers obeying the rules evolved to 1 after $\mathrm{T}=85$ times evolutions. The behaviors that were managed strictly by traffic managers evolved into behaviors that were managed carelessly after $\mathrm{T}=$ 63 times evolutions. Finally, the entire system evolved to a point of $(0.8583,1,0)$ under the above conditions.

Curves B31, B32, and B33 simulated the evolutionary trend of condition 3. In Figure 1, the crossing pedestrians all evolved into pedestrians obeying the rules after $\mathrm{T}=46$ times evolutions. Different from the pedestrian evolution trend, the behavior of vehicle drivers was no longer obeying traffic rules after $\mathrm{T}=67$ times evolutions. Affected by pedestrians' violation and their own revenue, the proportion of strict management rose with the evolution of time after $\mathrm{T}=152$ times evolutions.

In terms of times evolutions, all of them evolved into the behaviors of strict management. Under the effect of condition 3, the whole system gradually evolved to a point of $(1,0,1)$.

Curves B41, B42, and B43 simulate the evolutionary trend of condition 4. In Figure 1, the proportion of pedestrians obeying the rules and the proportion of traffic managers' management strictly evolved to 0 . This led to the gradual evolution of crossing pedestrians to risk violation of the crowd. Meanwhile, traffic managers were no longer able to manage strictly, leading pedestrians and vehicle drivers to violation. Compared with the behavior of the above two groups, after the behavior of the vehicle driver passed $\mathrm{T}=42$ times evolutions, the risk violations of the vehicle driver disappeared, and all evolved into the behavior of obeying the rules. Eventually, the entire system evolved to a point of $(0,1,0)$.

By comparing the above 12 curves, we found that under the same revenue conditions, pedestrians, vehicle drivers, and traffic managers had path dependence. For crossing pedestrians, when $e_{2}-2 e_{3}+p_{5} L 1+m<0$, they chose to risk violations, and vice versa, they chose follow the rules. For vehicle drivers, when $e_{5}-2 e_{4}+p_{5} L 2+M>0$, they chose to follow the rules, and vice versa, they chose to risk violations. For traffic managers, when $C_{1}-e_{1}-m-M+m p_{1}+M p_{2}-D>0$, they chose to manage carelessly, and vice versa, they chose to manage strictly. 


\subsection{Behavior Evolution Path Analysis Based on Sensitivity Simulation}

In order to facilitate the analysis of the evolution process of pedestrians, vehicle drivers, and traffic managers under different parameters, we simulated the influence of simulation model parameters on the behavior evolution path on the basis of the above analysis of evolutionary stability strategy.

(1) The impact of $D$ on behavioral evolution paths. Taking the above parameters as the standard, we set $D$ values to $20.5,21.5$, and 22.5. MATLAB simulation was used to obtain the following results.

As can be seen from Figure 2, different accountability losses had different impacts on pedestrians, vehicle drivers, and traffic managers. It can be seen from Figure $2 \mathrm{c}$ that with the increase of accountability losses, the probability of strict management by a traffic manager at the initial stage $(T<50)$ increased correspondingly but then declined, resulting in a decline in the probability of strict management by the traffic manager. Affected by the strict management behavior of the traffic manager, the probability of crossing pedestrians and vehicle drivers who obeyed rules was improved. Compared with crossing pedestrian behavior, the behavior of vehicle drivers presented different evolutionary trends. Under the influence of incomplete information, the probability of vehicle drivers obeying rules increased and eventually converged to 1 .

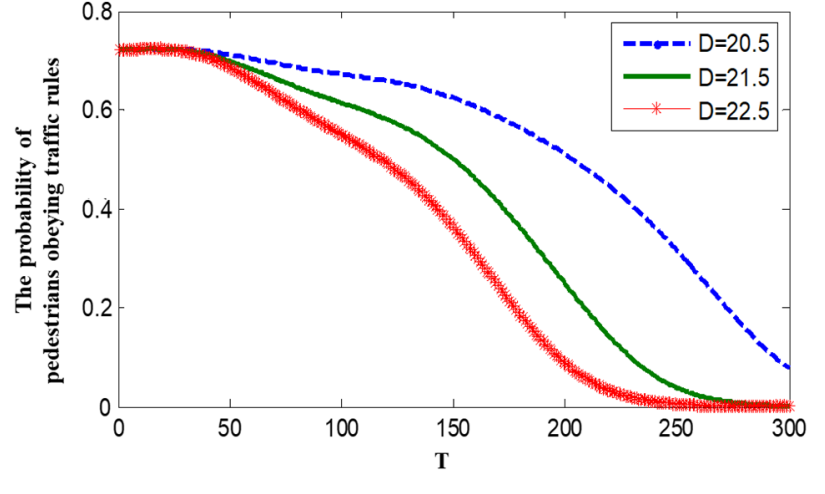

(a)

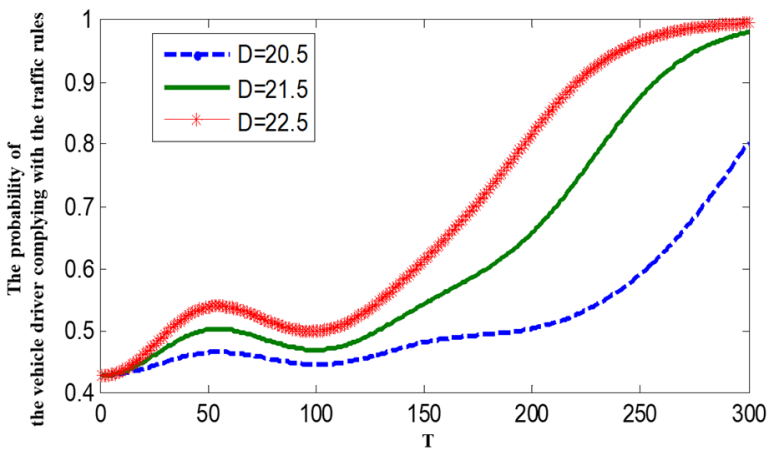

(b)

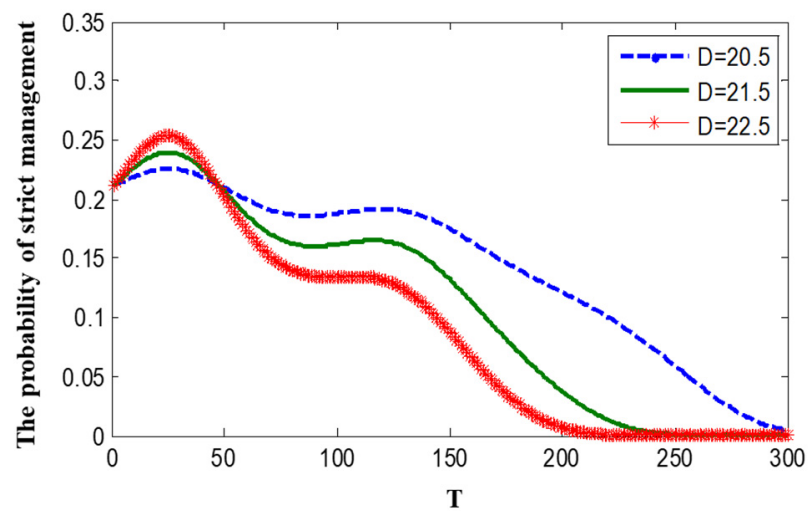

(c)

Figure 2. Simulation diagram of traffic managers' loss as a result of accountability. (a) pedestrians obeying traffic rules; (b) the vehicle driver complying with the traffic rules; (c) strict management.

(2) The impact of $e_{2}$ on behavioral evolution paths. Taking the above parameters as the standard, $e_{2}$ values were set to 5,8 , and 10. MATLAB simulation was used to obtain the following results.

It can be seen from Figure $3 a$ that the revenue of the pedestrians obeying the rules delayed the rate at which the proportion of pedestrians obeying the rules converged to 0 , 
and higher revenue at the same time meant a higher proportion of obeying traffic rules. From Figure $3 c$, one can see that high revenue meant that traffic managers were at a high level of strict management. The increase in the revenue of pedestrians led to an increase in the proportion of pedestrians obeying the rules. This gave vehicles drivers an opportunity to violate the rules, which aggravated the violation of the drivers' behavior and delayed the rate at which the drivers' compliance with the rules converged to 1.

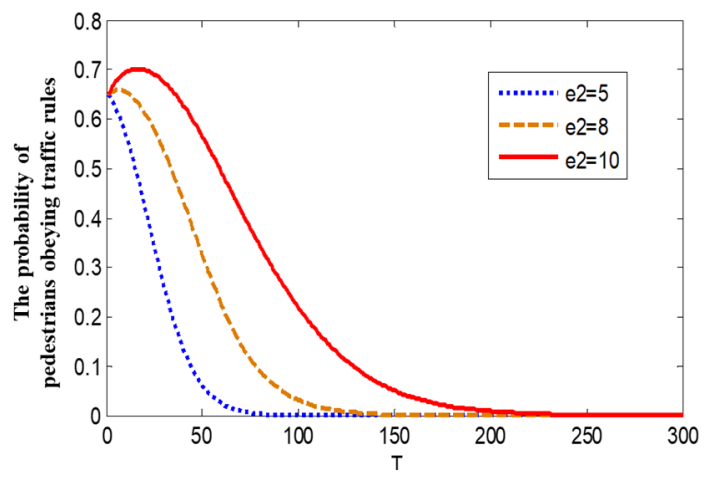

(a)

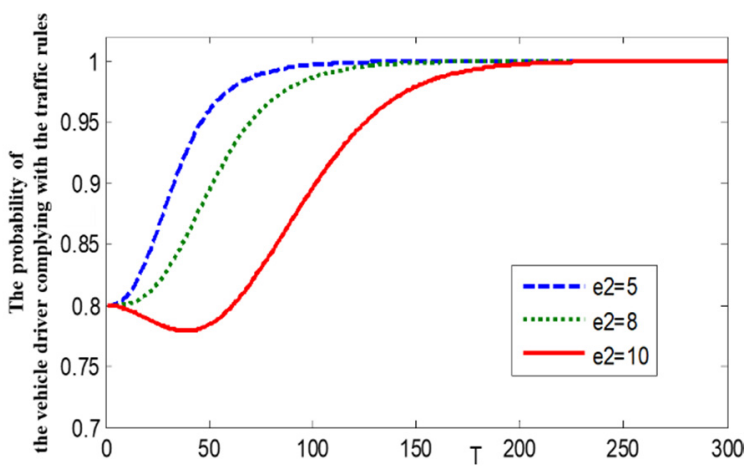

(b)

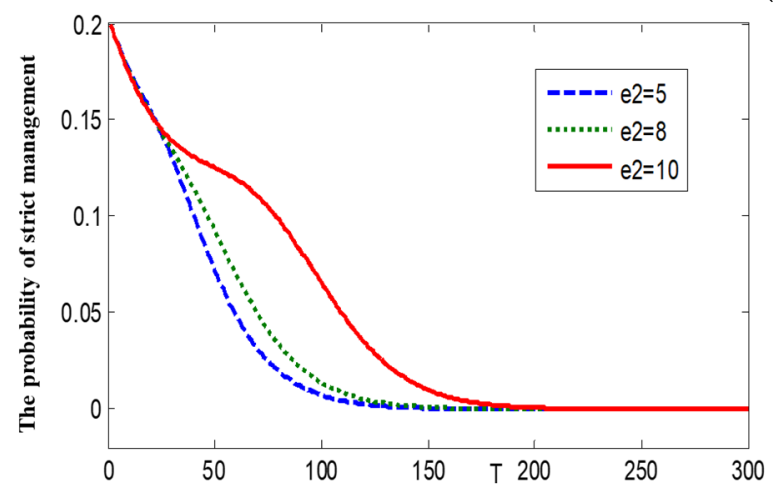

(c)

Figure 3. Simulation diagram of revenue generated by pedestrians obeying the rules. (a) pedestrians obeying traffic rules; (b) the vehicle driver complying with the traffic rules; (c) strict management.

(3) The impact of $e_{5}$ on behavioral evolution paths. Taking the above parameters as the standard, we set $e_{5}$ values to 4,6 , and 8 . MATLAB simulation was used to obtain the following results.

From Figure $4 b$, one can see that the greater the safety revenue generated by drivers obeying rules, the faster the proportion of vehicle drivers following the rules converged to 1 . Affected by vehicle drivers' compliance with the rules, the behavior of pedestrians obeying the rules had a downward trend with the increase of revenue of obeying the rules. Higher safety revenue accelerated the rate at which traffic managers managed carelessly that converged to 0 . With the gradual negligence of traffic managers, the proportion of pedestrians obeying to the rules gradually declined and eventually converged to 0 . 


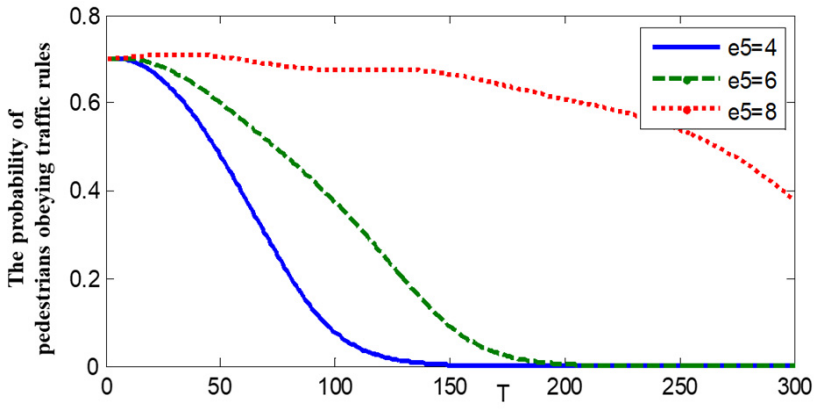

(a)

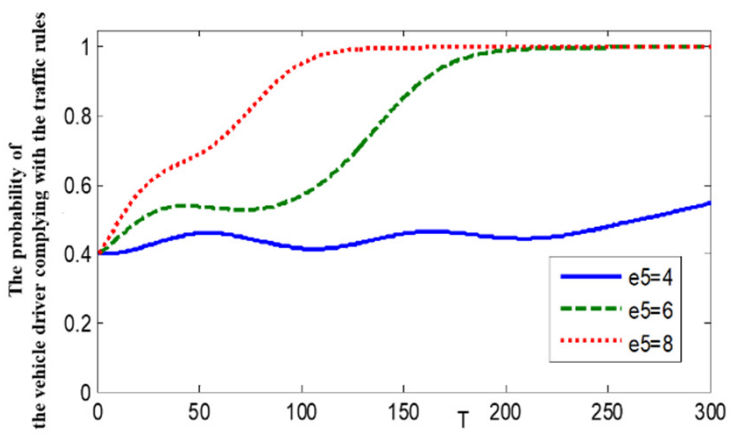

(b)

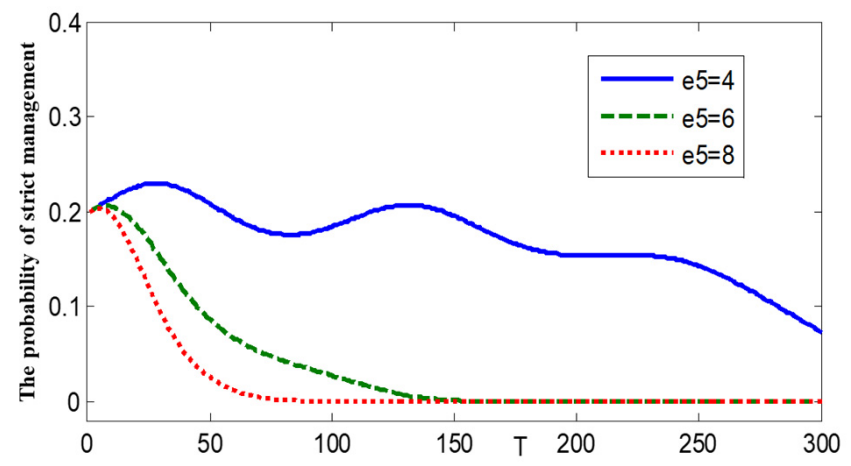

(c)

Figure 4. Simulation diagram of driver safety revenue generated by drivers obeying the rules. (a) pedestrians obeying traffic rules; (b) the vehicle driver complying with the traffic rules; (c) strict management.

(4) The impact of $e_{4}$ on behavioral evolution paths. Taking the above parameters as the standard, we set $e_{4}$ values to 15,20 , and 25. MATLAB simulation was used to obtain the following results.

It is shown in Figure $5 b$ that the time revenue obtained by vehicle drivers' violation delayed the rate at which the proportion of compliance behaviors converged to 1 and had a certain inhibitory effect on the behavior of obeying the rules. The increase in time revenue had a positive effect on the violation behavior of vehicle drivers, which made traffic managers have to manage traffic strictly. As a result, the amount of strict management by traffic managers gradually increased. The strict management of traffic managers curbed the occurrence of crossing pedestrian violations. This is reflected in the figure showing that high revenue was more likely to converge to 0 than low revenue at the same time.

In summary, by simulating the influence of relevant factors on the behavioral evolution path, we have described the interaction mechanism between traffic subject behaviors, proving that the balance of behavioral evolution strategies of pedestrians, vehicle drivers, and traffic managers are not only dependent on self-revenue but also on those of the other two groups. 


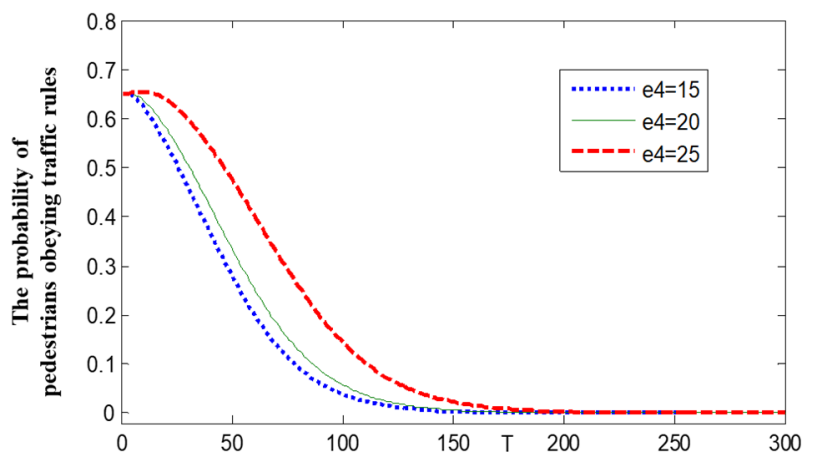

(a)

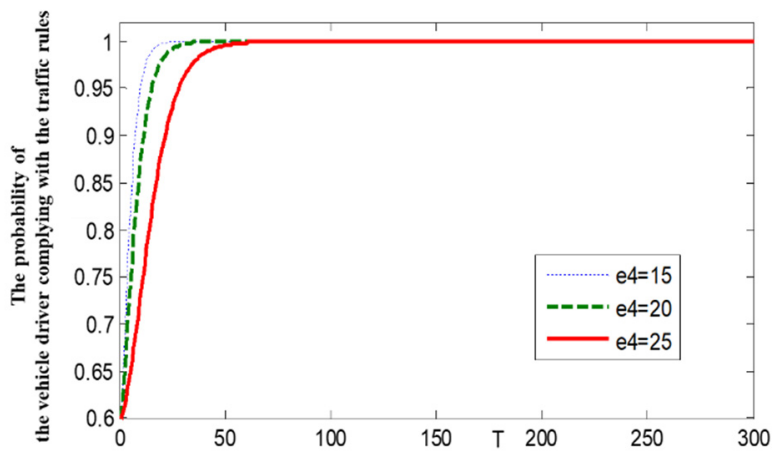

(b)

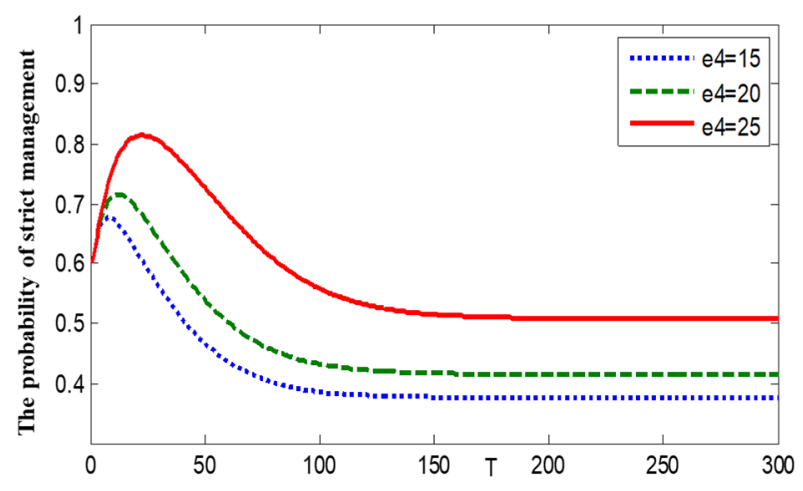

(c)

Figure 5. Simulation diagram of driver time revenue generated by drivers' violation. (a) pedestrians obeying traffic rules; (b) the vehicle driver complying with the traffic rules; (c) strict management.

\section{Conclusions}

This paper used evolutionary game theory to systematically model the long-term evolution of pedestrians, vehicle drivers, and traffic managers. Through the analysis of the evolutionary stability strategy, we found that the dynamic replication system con-verged to the crossing pedestrians and the vehicle drivers violating the regulations, causing the traffic managers manage strictly. The micro-mechanism and social complexity of the interaction between traffic subjects were analyzed. By analyzing the sensitivity of behavioral influencing factors, we discuss the influence degree of each factors on the behavior of traffic participants. The behavioral factors affecting the traffic participants included the revenue factor and the limiting factor, and the evolution process of the traffic participants' behavior was completed under the role of two factors. The balance of behavioral evolution strategies of pedestrians, vehicle drivers, and traffic managers were not only dependent on their own revenue, but also on those of the other two groups.

Compared with the behavioral simulation of the one-time street crossing process, this paper took the evolution thought of as the research paradigm and considered the traffic subject behavior into the traffic environment in order to expand the research perspective and research method of the traffic behavior and simulation system, so as to more effectively reflect and explain the evolution process and laws of the traffic subject behavior and provide a new idea for solving the conflict of interest at the crosswalk of the road section. In this paper, the conclusion can provide the traffic administrative department of the management of road traffic with a decision-making basis, a city state and regional average for road intersection traffic safety, and traffic conflict rate control standards for pedestrians and motor vehicles; provide road intersection probability of mutual concession; promote the comity pedestrian and vehicle driver; and improve traffic efficiency, reasonable distribution of traffic flow, and strict traffic control. 
Author Contributions: The authors confirm contribution to the paper as follows: data curation, Z.W.; formal analysis, H.G.; methodology, R.Z. and S.Q.; writing-original draft, R.Z. and H.G.; writing-review and editing, Z.W. and S.Q. All authors reviewed the results and approved the final version of the manuscript.

Funding: This research was supported by Basic Research Fund of Beijing University of Technology (grant no. 038000546318503) and International Research Cooperation Seed Fund of Beijing University of Technology (grant no. 038000514119004).

Institutional Review Board Statement: Not applicable.

Informed Consent Statement: Informed consent was obtained from all subjects involved in the study.

Data Availability Statement: No new data were created or analyzed in this study. Data sharing is not applicable to this article.

Conflicts of Interest: The authors declare no conflict of interest.

\section{References}

1. Hamed, M.M. Analysis of pedestrians' behavior at pedestrian crossings. Saf. Sci. 2001, 38, 63-82. [CrossRef]

2. Tanaboriboon, Y.; Jing, Q. Chinese pedestrians and their walking characteristics: Case study in Beijing. Transp. Res. Rec. 1994, 1441, 16-26.

3. Yagil, D. Beliefs, motives and situational factors related to pedestrians' self-reported behavior at signal-controlled crossings. Transp. Res. Part F Traffic Psychol. Behav. 2000, 3, 1-13. [CrossRef]

4. Sisiopiku, V.P.; Akin, D. Pedestrian behaviors at and perceptions towards various pedestrian facilities: An examination based on observation and survey data. Transp. Res. Part F Traffic Psychol. Behav. 2003, 6, 249-274. [CrossRef]

5. Das, S.; Manski, C.F.; Manuszak, M.D. Walk or wait? An empirical analysis of street crossing decisions. J. Appl. Econom. 2005, 20, 529-548. [CrossRef]

6. Finnis, K.K.; Walton, D. Field observations to determine the influence of population size, location and individual factors on pedestrian walking speeds. Ergonomics 2008, 51, 827-842. [CrossRef]

7. Holland, C.; Hill, R. The effect of age, gender and driver status on pedestrians' intentions to cross the road in risky situations. Accid. Anal. Prev. 2007, 39, 224-237. [CrossRef] [PubMed]

8. Tian, H.H.; Wei, Y.F.; Yu, X.; Lu, W.Z. Lattice hydrodynamic model with bidirectional pedestrian flow. Phys. A Stat. Mech. Its Appl. 2009, 388, 2895-2902. [CrossRef]

9. Reason, J.; Manstead, A.; Stradling, S.; Baxter, J.; Campbell, K. Errors and violations on the roads: A real distinction? Ergonomics 1990, 33, 1315-1332. [CrossRef] [PubMed]

10. Zegeer, C.V.; Stutts, J.C.; Huang, H.; Zhou, M.; Rodgman, E. Analysis of elderly pedestrian accidents and recommended countermeasures. Transp. Res. Rec. 1993, 1405, 56-63.

11. Coffin, A.; Morrall, J. Walking Speeds of Ederly Pedestrians at Crosswalks. Transp. Res. Rec. 1995, 1487, 63.

12. Oxley, J.; Fildes, B.; Ihsen, E.; Charlton, J.; Day, R. Differences in traffic judgements between young and old adult pedestrians. Accid. Anal. Prev. 1997, 29, 839-847. [CrossRef]

13. Whitebread, D.; Neilson, K. The contribution of visual search strategies to the development of pedestrian skills by $4-11$ year-old children. Br. J. Educ. Psychol. 2000, 70, 539-557. [CrossRef] [PubMed]

14. Díaz, E.M. Theory of planned behavior and pedestrians' intentions to violate traffic regulations. Transp. Res. Part F Traffic Psychol. Behav. 2002, 5, 169-175. [CrossRef]

15. Tiwari, G.; Bangdiwala, S.; Saraswat, A.; Gaurav, S. Survival analysis: Pedestrian risk exposure at signalized intersections. Transp. Res. Part F Traffic Psychol. Behav. 2007, 10, 77-89. [CrossRef]

16. Avineri, E.; Shinar, D.; Susilo, Y.O. Pedestrians' behaviour in cross walks: The effects of fear of falling and age. Accid. Anal. Prev. 2012, 44, 30-34. [CrossRef] [PubMed]

17. Rosenbloom, T.; Hadari-Carmi, O.; Sapir-Lavid, Y. Actual and perceived social norms of children's road crossing behavior. Saf. Sci. 2012, 50, 175-180. [CrossRef]

18. Wang, L.; Xie, N.G.; Meng, R. Dirty-Face Game Analysis on Mixed Traffic Flow at Unsignalized Intersection. In Advanced Materials Research; Trans Tech Publications Ltd.: Stafa-Zurich, Switzerland, 2011; Volume 201, pp. 2119-2125.

19. Guo, J.Y.; Liu, S.; Chen, S.K.; Mao, B.H. Review of pedestrian movement simulation studies. J. Syst. Simul. 2008, 20, $2237-2241$.

20. Schwebel, D.C.; Severson, J.; Ball, K.K.; Rizzo, M. Individual difference factors in risky driving: The roles of anger/hostility, conscientiousness, and sensation-seeking. Accid. Anal. Prev. 2006, 38, 801-810. [CrossRef]

21. Lassarre, S.; Papadimitriou, E.; Yannis, G.; Golias, J. Measuring accident risk exposure for pedestrians in different microenvironments. Accid. Anal. Prev. 2007, 39, 1226-1238. [CrossRef] [PubMed]

22. Taubman-Ben-Ari, O.; Shay, E. The association between risky driver and pedestrian behaviors: The case of Ultra-Orthodox Jewish road users. Transp. Res. Part F Traffic Psychol. Behav. 2012, 15, 188-195. [CrossRef]

23. Gstalter, H.; Fastenmeier, W. Reliability of drivers in urban intersections. Accid. Anal. Prev. 2010, 42, 225-234. [CrossRef] 
24. Şimşekoğlu, Ö. How do attitudes, personality traits, and driver behaviors relate to pedestrian behaviors? A Turkish case. Traffic Inj. Prev. 2015, 16, 84-89. [CrossRef] [PubMed]

25. Salmon, P.M.; Lenne, M.G.; Walker, G.H.; Stanton, N.A.; Filtness, A. Using the Event Analysis of Systemic Teamwork (EAST) to explore conflicts between different road user groups when making right hand turns at urban intersections. Ergonomics 2014, 57, 1628-1642. [CrossRef]

26. Zhou, R.; Horrey, W.J.; Yu, R. The effect of conformity tendency on pedestrians' road-crossing intentions in China: An application of the theory of planned behavior. Accid. Anal. Prev. 2009, 41, 491-497. [CrossRef] [PubMed]

27. Barton, B.K.; Kologi, S.M.; Siron, A. Distracted pedestrians in crosswalks: An application of the Theory of Planned Behavior. Transp. Res. Part F Traffic Psychol. Behav. 2016, 37, 129-137. [CrossRef]

28. Nagatani, T. Jamming and freezing transitions in CA model for facing pedestrian traffic with a soft boundary. Phys. Lett. A 2010, 374, 1686-1689. [CrossRef]

29. Dou, S.; Li, X.; Gou, J. Study on urban road intersection traffic scenario simulation based on cellular automaton. Adv. Transp. Stud. 2013, 32, 149-160.

30. Zhou, X.F.; Zheng, C.J. An Analysis of Road-grabbing at Non-intersection Crosswalks without Signal Control Based on Game Theory. J. East China Jiaotong Univ. 2012, 6, 65-69.

31. Kim, J.; Tak, S.; Bierlaire, M.; Yeo, H. Trajectory Data Analysis on the Spatial and Temporal Influence of Pedestrian Flow on Path Planning Decision. Sustainability 2020, 12, 10419. [CrossRef]

32. Xiao, Z.; Zhou, Z.; Zhang, K. Pedestrians' violation behavior model based on group decision-making. Adv. Mech. Eng. 2019, 11. [CrossRef]

33. Saleh, W.; Grigorova, M.; Elattar, S. Pedestrian Road Crossing at Uncontrolled Mid-Block Locations: Does the Refuge Island Increase Risk? Sustainability 2020, 12, 4891. [CrossRef]

34. Kim, H.M.; Mateo-Babiano, I. Pedestrian Crossing Environments in an Emerging Chinese City: Vehicle Encountering, Seamless Walking, and Sensory Perception Perspectives. Sustainability 2018, 10, 2200. [CrossRef]

35. Wang, Y.; Shen, B.; Wu, H.; Wang, C.; Su, Q.; Chen, W. Modeling illegal pedestrian crossing behaviors at unmarked mid-block roadway based on extended decision field theory. Phys. A: Stat. Mech. Its Appl. 2021, 562, 125327. [CrossRef]

36. He, G.G.; Ji, Y.M.; Liu, F.T. Choice for travel modes based on the two-level game. J. Chang'an Univ. (Soc. Sci. Ed.) 2006, 8, 4-7. 